\title{
Chapter 1. Significance of CKD
}

- The number of dialysis patients due to end-stage kidney disease is increasing worldwide, which is becoming a burden on health economics.

- End-stage kidney disease due to diabetic nephropathy is increasing worldwide.

- The development of chronic kidney disease (CKD) is associated with atherosclerosis caused by lifestylerelated diseases such as diabetes and hypertension.

- CKD is most likely to cause cardiovascular disease, hospitalization or death, thus threatening nations' health.

The number of end-stage kidney disease patients is ever-increasing in Japan as well as the rest of the world

- The number of end-stage kidney disease (ESKD) patients requiring dialysis or renal transplantation is increasing markedly in every part of the world. It is predicted that the number of such patients will increase as much as fivefold from 430,000 to 2,100,000 over a 20-year period from 1990 to 2010 . This rapid increase can be appreciated when compared to the prediction that diabetes patients will increase by about 1.7 times during the 22-year period from 2003 to 2025 .

- Regarding hemodialysis patients, there will be $2,100,000$ patients in 2,010 in the world and oneseventh of them will be Japanese (Fig. 1-1). Japan is thus the most densely populated country in the world by dialysis patients in terms of the number of patients per unit population, and the number of such patients still keeps on rising.
CKD patients are reserves of ESKD: CKD is a common disease

- CKD is worthy of attention, as these patients represent a reserve for ESKD that continues to increase throughout the world. In the United States, the prevalence of CKD patients in CKD stage 3-5 [estimated glomerular filtration rate $\left.(\mathrm{eGFR})<60 \mathrm{~mL} / \mathrm{min} / 1.73 \mathrm{~m}^{2}\right]$ has been estimated at $4.6 \%$ (i.e. $8,300,000$ ) of the adult population. According to the Japanese Society of Nephrology, Japan has far more CKD patients than the United States: CKD patients with GFR $<60 \mathrm{~mL} / \mathrm{min} / 1.73 \mathrm{~m}^{2}$ represent $10.6 \%$ of the general population aged 20 years or older (around $10,970,000)$; those with $\mathrm{GFR}<50 \mathrm{~mL} / \mathrm{min} / 1.73 \mathrm{~m}^{2}$

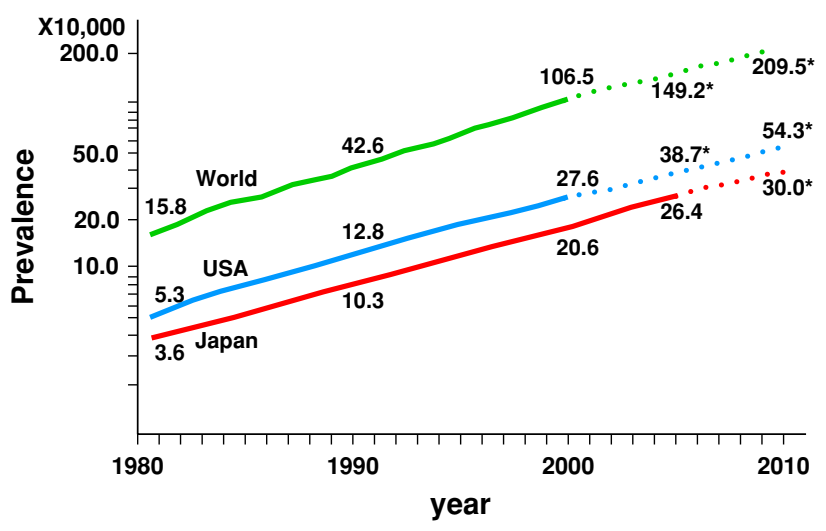

Fig. 1-1 Changes in prevalence of hemodialysis patients (worldwide, United States, and Japan). The numbers of patients on maintenance dialysis in the world, the United States (USA) and Japan are shown in logarithmic scale. The estimated data for the world and the United States are quoted, with modification, from Lysaght (J Am Soc Nephrol 2002;13:S37-S40). The number of Japanese patients is according to the current status of chronic dialysis therapy in Japan (as of 31 December 2007) published by The Japanese Society for Dialysis Therapy http://www.jsdt.or.jp/ 
represent $3.1 \%(3,160,000)$ (Table $1-1)$. These numbers suggest that $\mathrm{CKD}$ is a common disease encountered very often in daily clinical practice (see Table 1-2).

\section{CKD is an important disease group that threatens human health}

- A decline in kidney function is an important risk factor for cardiovascular disease (CVD). The poorer the

Table 1-1 Distribution of glomerular filtration rate (GFR) in the adult Japanese population

\begin{tabular}{lcl}
\hline GFR $\left(\mathrm{mL} / \mathrm{min} / 1.73 \mathrm{~m}^{2}\right)$ & Number $(\times 1,000)$ & $(\%)$ \\
\hline$\geq 90$ & 28,637 & 27.75 \\
$60-89$ & 63,579 & 61.61 \\
$50-59$ & 7,809 & $7.57^{\mathrm{a}}$ \\
$40-49$ & 2,363 & $2.29^{\mathrm{a}, \mathrm{b}}$ \\
$30-39$ & 569 & $0.55^{\mathrm{a}, \mathrm{b}}$ \\
$15-29$ & 191 & $0.19^{\mathrm{a}, \mathrm{b}}$ \\
$<15$ & 45 & $0.04^{\mathrm{a}, \mathrm{b}}$ \\
Total & 103,193 & 100.00
\end{tabular}

Approximately 275,000 patients on dialysis are not included in the group of GFR $<15 \mathrm{~mL} / \mathrm{min} / 1.73 \mathrm{~m}^{2}$ )

${ }^{\text {a }}$ Number of people with GFR $<60$ is 10.98 million in adults $(10.64 \%)$

b Number of people with GFR $<50$ is 3.17 million in adults $(3.07 \%)$

Data source: HMO insurance (Kaiser
Permanente)
Age: 20 yrs and over (mean 52 yrs)
Subjects: $>1.12$ million
Duration: mean 2.84 years
M/F=9 : 11

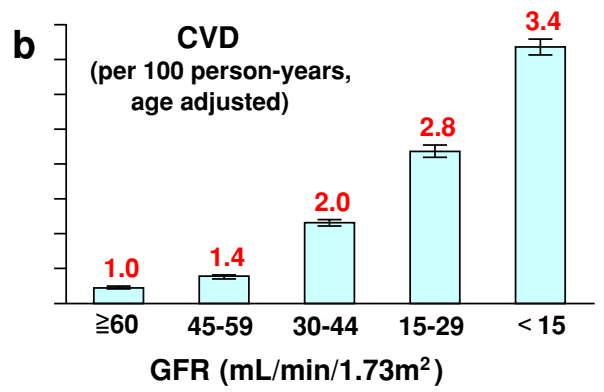

Fig. 1-2 Relative risks for death, cardiovascular events, and hospitalization by kidney function (GFR). The results shown are taken from an epidemiologic survey on the incidence of death, cardiovascular event, and hospitalization by kidney function in people insured by the HMO Insurance Kaiser Permanente. A total of 112,000 people 20 years of age or older (mean observation period 2.84 years, mean kidney function, the higher the risk of CVD. Besides CVD, a large-scale epidemiological investigation revealed that relative risks for total mortality or hospitalization rise irrespective of cause in proportion to the degree of reduction in kidney function (Fig. 1-2). It was also shown in an epidemiological study conducted in Japan that CKD is a risk factor for CVD development and death, establishing CKD as an important syndrome that jeopardizes the health of Japanese people (Figs. 1-3, 1-4).

Table 1-2 Prevalence of chronic kidney disease (CKD) in the adult Japanese population

\begin{tabular}{lllll}
\hline CKD stage & $\begin{array}{l}\text { GFR } \\
(\mathrm{mL} / \mathrm{min} / \\
\left.1.73 \mathrm{~m}^{2}\right)\end{array}$ & \multicolumn{1}{l}{$\begin{array}{l}\text { Number } \\
\text { of CKD } \\
\text { patients }\end{array}$} \\
\hline 1 & $\geq 90$ & & 605,313 & \\
2 & $60-89$ & & $1,708,870$ & \\
3 & $30-59$ & & $10,743,236$ & \\
& & $50-59$ & & $7,809,261$ \\
& & $40-49$ & & $2,363,987$ \\
4 & & $30-39$ & & 569,988 \\
5 & $15-29$ & & 191,045 & \\
\hline
\end{tabular}

The number of patients with CKD stage 1 and 2 was estimated according to the presence of proteinuria. Patients on dialysis and renal transplantation are not included in CKD stage 5

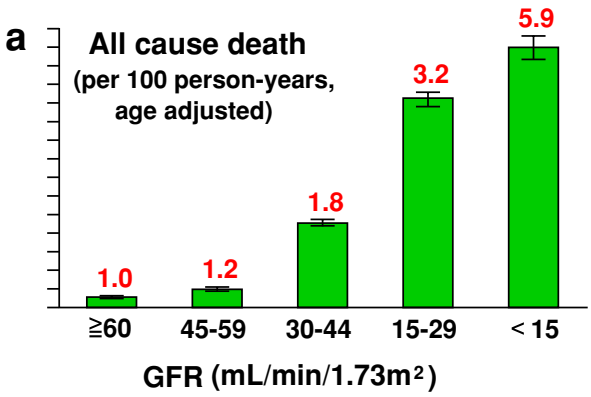

c

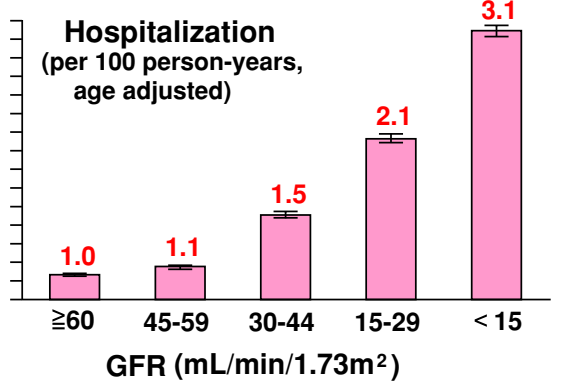

age 52 years, male to female ratio 9:11) were surveyed. Relative risk of death in total (per 100 patients per year), relative risk of cardiovascular event (per 100 patients per year), and relative risk of hospitalization in total (per 100 patients per year) were corrected for age. The data reported are taken, with modification, from Go et al. (N Engl J Med 2004;351:1296-1305) 

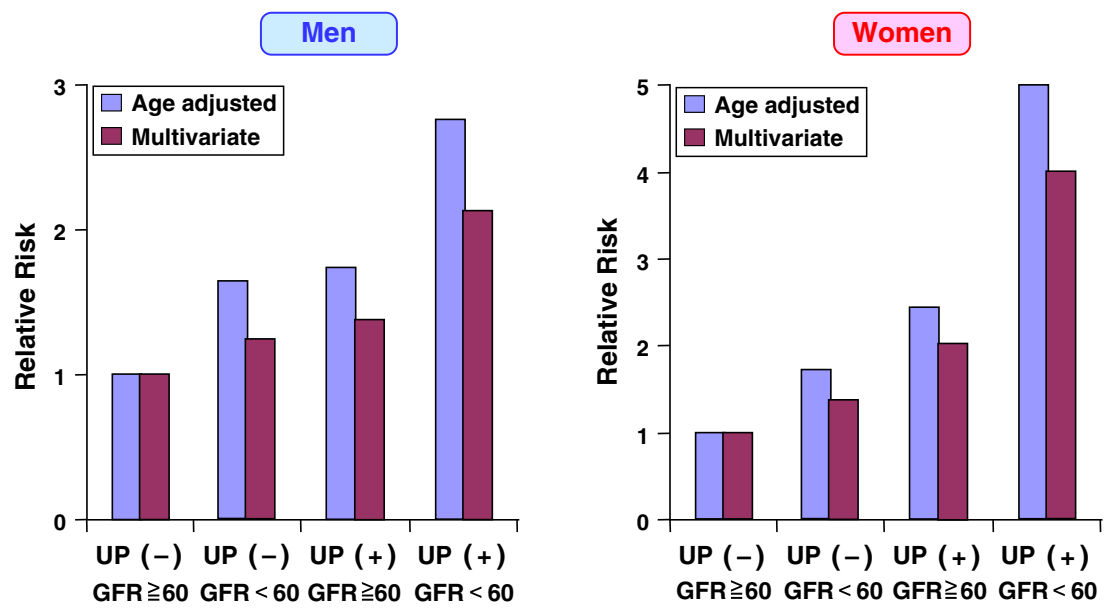

(General population : men 30,764 , women 60,668 , age $40-79$ yrs )

(reference: GFR $\geqq 60$, proteinuria $(-)$ )

GFR $60 \mathrm{~mL} / \mathrm{min} / 1.73 \mathrm{~m}^{2}$ is equal to $53 \mathrm{~mL} / \mathrm{min} / 1.73 \mathrm{~m}^{2}$ by Japanese formula.

Ibaraki screening study on 1993. Adjusted for age, hypertension category, smoking, alcohol, DM, total cholesterol, HDL-C, and BMI

Irie F et al.: Kidney Int., 69, 1264-1271, 2005.

Fig. 1-3 Relative risk of death from cardiovascular events according to the presence or absence of proteinuria and kidney function level. The relative risk was regarded as 1.0 for the group of participants in the general health examination. There were 30,704 male and 60,668 female participants aged $40-79$ years, having GFR $\geq 60 \mathrm{~mL} / \mathrm{min} /$
$1.73 \mathrm{~m}^{2}$ and no proteinuria. The data reported are taken, with modification, from Irie et al. (Kidney Int 2005;69:1264-1271). The value of GFR $60 \mathrm{~mL} / \mathrm{min} / 1.73 \mathrm{~m}^{2}$ cited in this paper corresponds to about $53 \mathrm{~mL} / \mathrm{min} / 1.73 \mathrm{~m}^{2}$ as calculated by the estimation formula for GFR devised for Japanese people
Fig. 1-4 The incidence of cardiovascular disease and its relative risk in relation to the presence or absence of CKD (from the Hisayama Study). Hisayama Study: age 40 years and over, men 1,110 , women 1,524 , follow-up 12 years (1988-2000), excluded those with history of stroke or acute myocardial infarction. CKD (+) denotes GFR $<60 \mathrm{~mL} / \mathrm{min} /$ $1.73 \mathrm{~m}^{2}$. a A cumulative incidence of ischemic heart disease (IHD) [data taken from Ninomiya $T$ et al. Sogo Rinsho 2006;55:1248-1254]. b Relative risks [data taken, with modification, from Ninomiya $\mathrm{T}$ et al. Kidney Int 2005;68:228236]
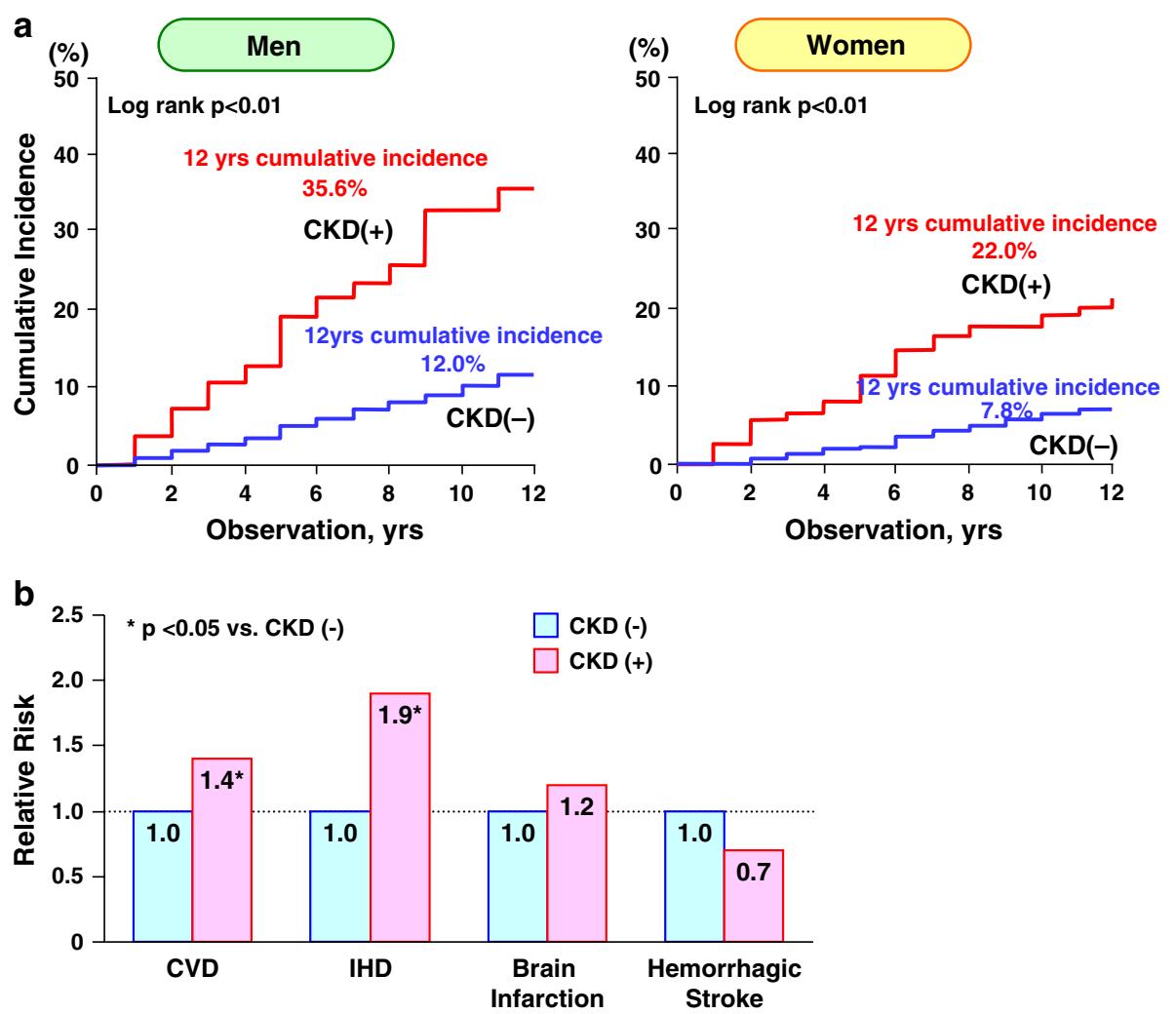


\section{Tasks for CKD management in Japan}

- As mentioned above, CKD is critical among the groups of illnesses threatening the nation's health, and there is a need for the whole nation to cope with CKD. There are four aspects of the task of promoting CKD management efficiently and continually as outlined in the following:

(1) To research the actual conditions of CKD in order to collect epidemiological data on risk factors for CKD, comorbidities, and prognoses. To develop a Japanese formula to estimate GFR that is tailored for Japanese people.

(2) To publish a clinical practice guidebook for CKD. To set up a system involving cooperation with primary care physicians and comedical staff in order to promote CKD management efficiently.

(3) To advertise the importance of CKD to citizens, patients, medical professionals, and government, and ensure that this is reflected in health policy.

(4) To exchange useful knowledge with the international CKD community. 